\title{
408.
}

\section{ADDITION TO MEMOIR ON THE RESULTANT OF A SYSTEM OF TWO EQUATIONS.}

[From the Philosophical Transactions of the Royal Society of London, vol. CLVIII. (for the year 1868), pp. 173-180. Received August 6,-Read November 21, 1867.]

The elimination tables in the Memoir on the Resultant of a System of two Equations, Phil. Trans. 1857 , pp. 703-715, [148], relate to equations of the form $(a, b \ldots \gamma x, y)^{m}=0$, without numerical coefficients; but it is, I think, desirable to give the corresponding tables for equations in the form $(a, b, \ldots \gamma x, y)^{m}=0$ with numerical coefficients, which is the standard form in quantics. The transformation can of course be effected without difficulty, and the results are as here given. It is easy to see $\grave{a}$ priori that the sum of the numerical coefficients in each table ought to vanish; these sums do in fact vanish, and we have thus a verification as well of the tables of the present Addition as of the tables of the original memoir, by means whereof the present tables were calculated.

Table (2, 2).

Resultant of

$(a, b, c \gamma x, y)^{2}$,

$\left(p, q, r_{\chi} x, y\right)^{2}$.

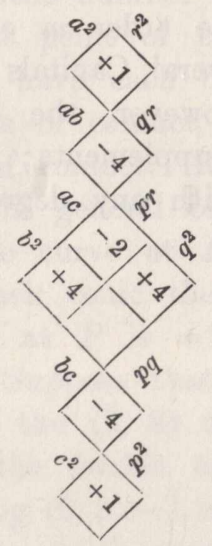

Table (3, 2).

Resultant of

$\left(a, b, c, d \gamma(x, y)^{3}\right.$,

$(p, q, r \gamma x, y)^{2}$.

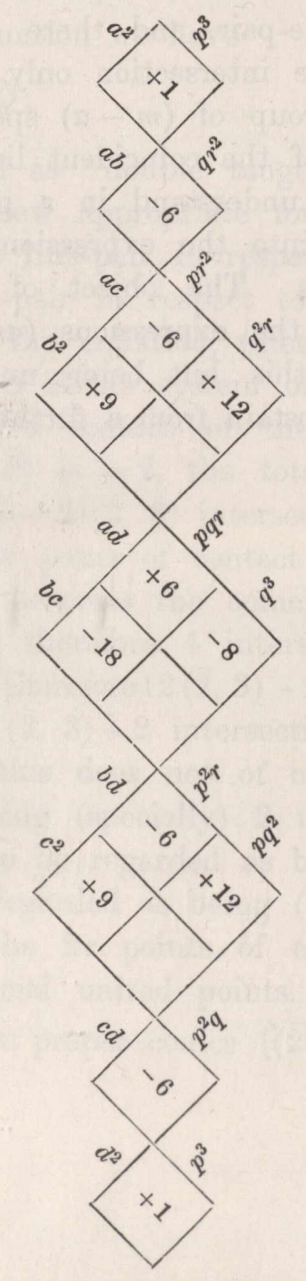


Table (4, 2).

Resultant of

$\left(a, b, c, d, e \gamma(x, y)^{4}\right.$, $\left(p, q, r \gamma(x, y)^{2}\right.$.

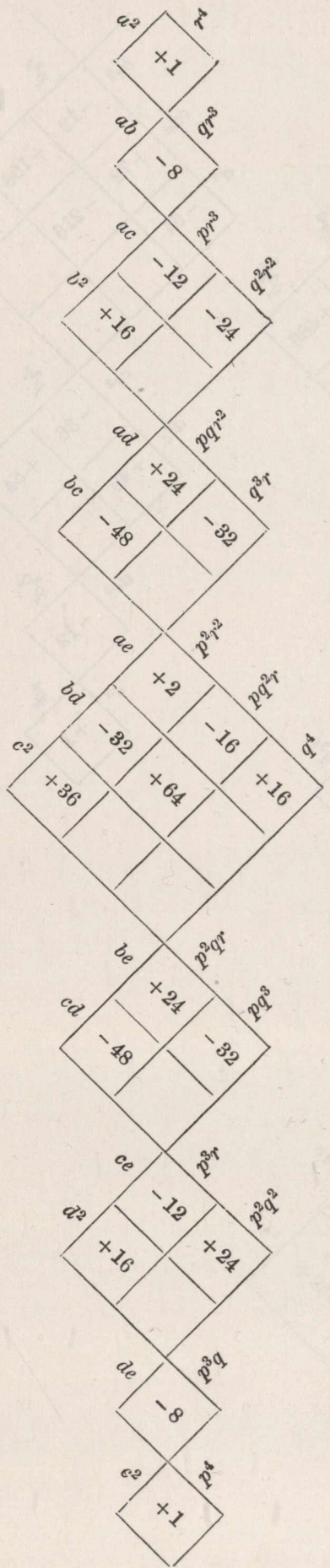

Table $(3,3) *$.

Resultant of

$\left(a, b, c, d \gamma(x, y)^{3}\right.$,

$\left(p, q, r, s \gamma(x, y)^{3}\right.$.

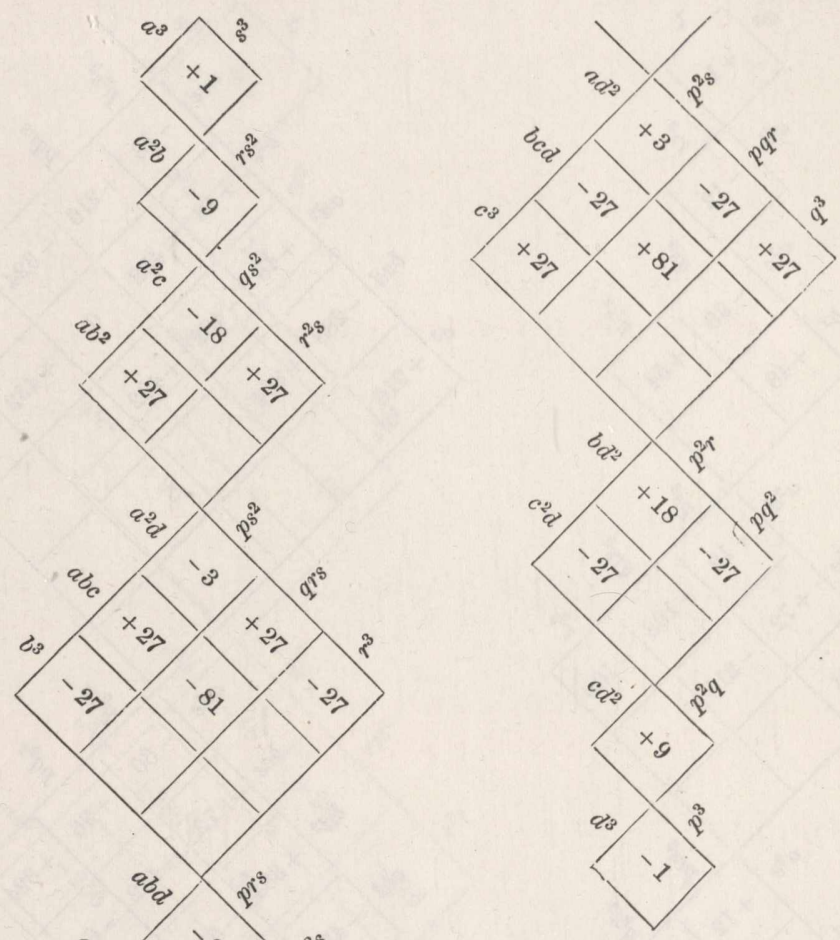

* N.B. In the corresponding table of the memoir, there is an error in the signs of the last two terms; they should be
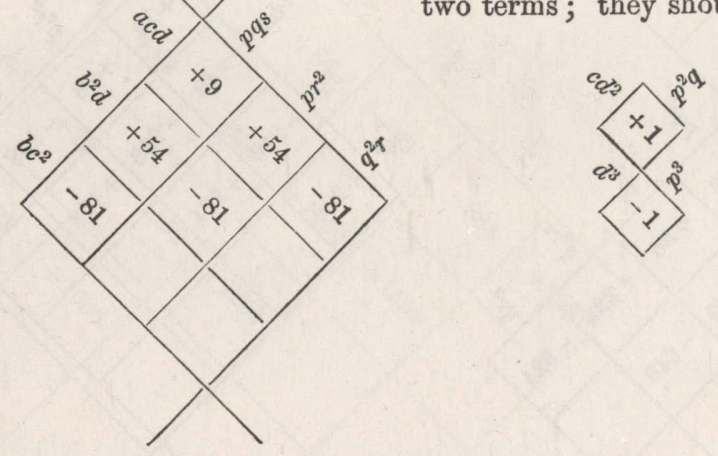
Table $(4,3)$.

Resultant of

$\left(a, b, c, d, e^{\gamma}(x, y)^{4}\right.$,

$(p, q, r, s\} x, y)^{3}$.
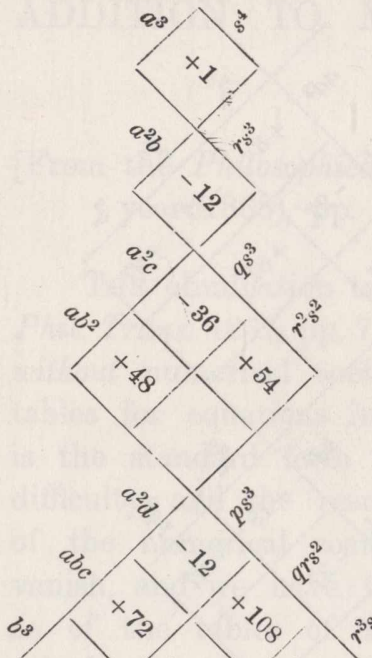

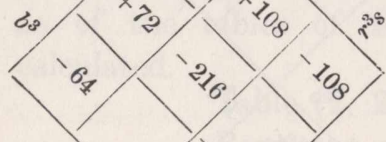
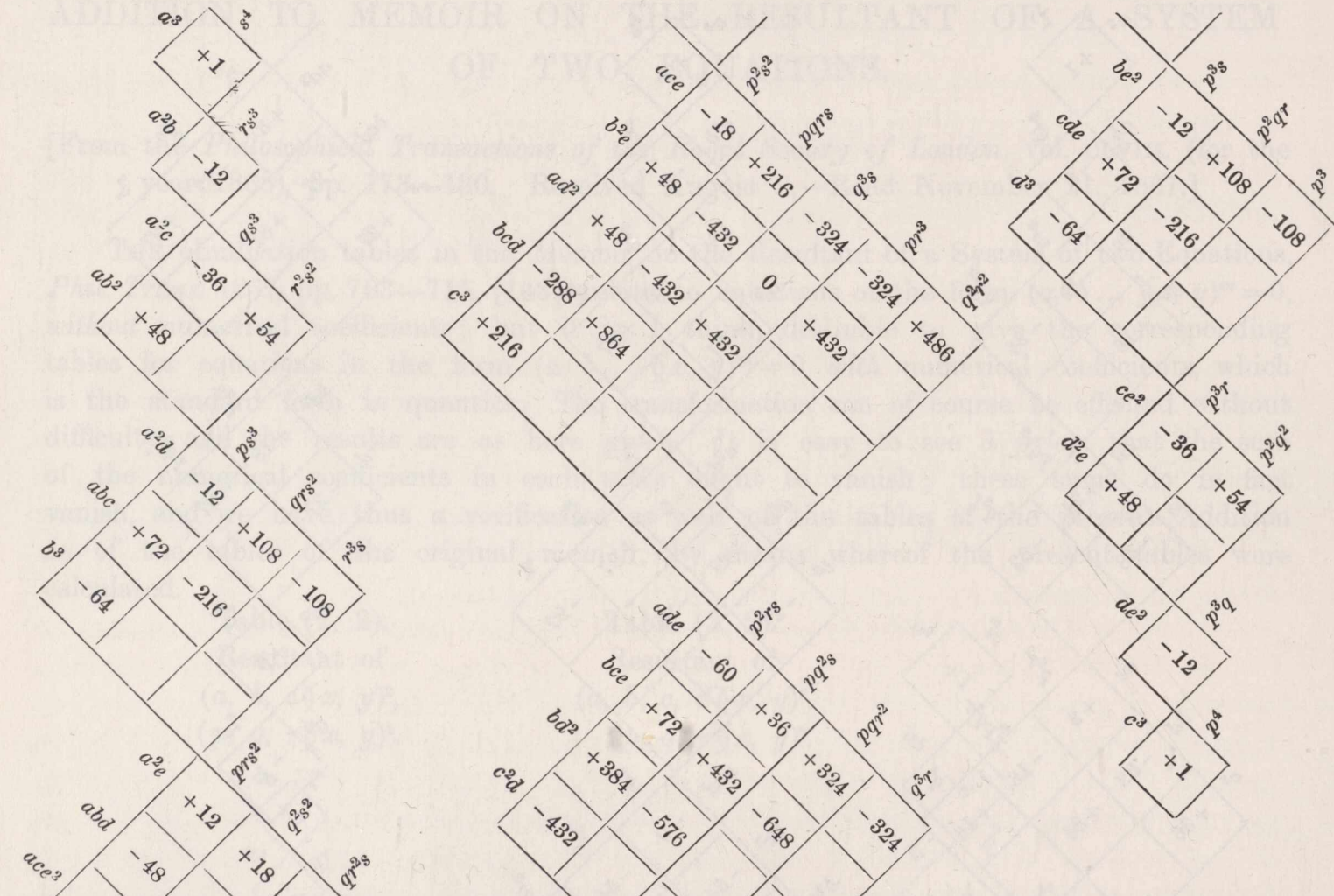

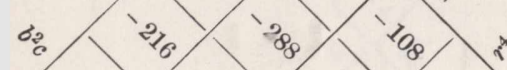

每

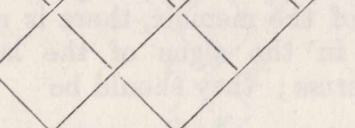

$8^{8} \times p^{a^{2}}$

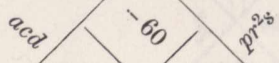

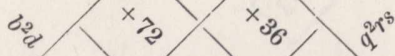

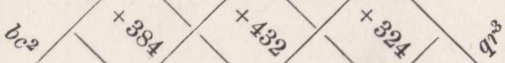

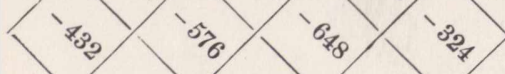
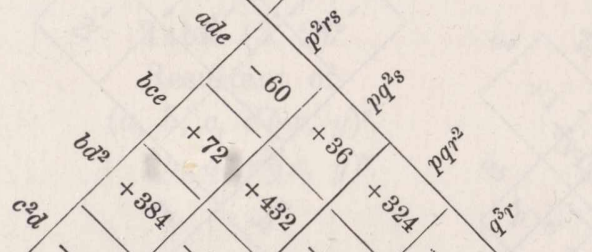

级

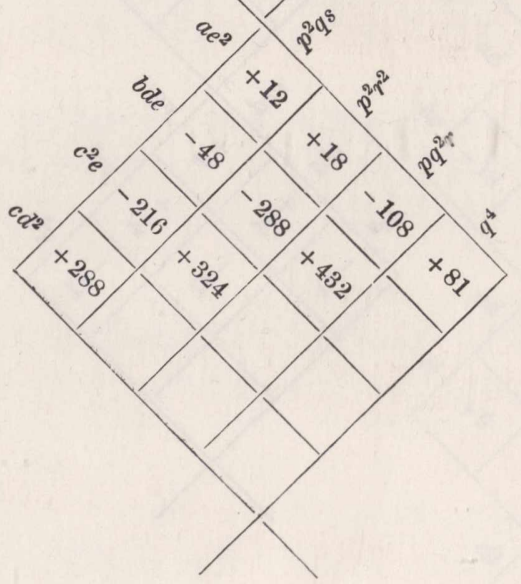


Table (4, 4).

Resultant of

$\left(a, b, c, d, e^{\gamma} x, y\right)^{4}$,

$\left(p, q, r, s, t \gamma(x, y)^{4}\right.$.

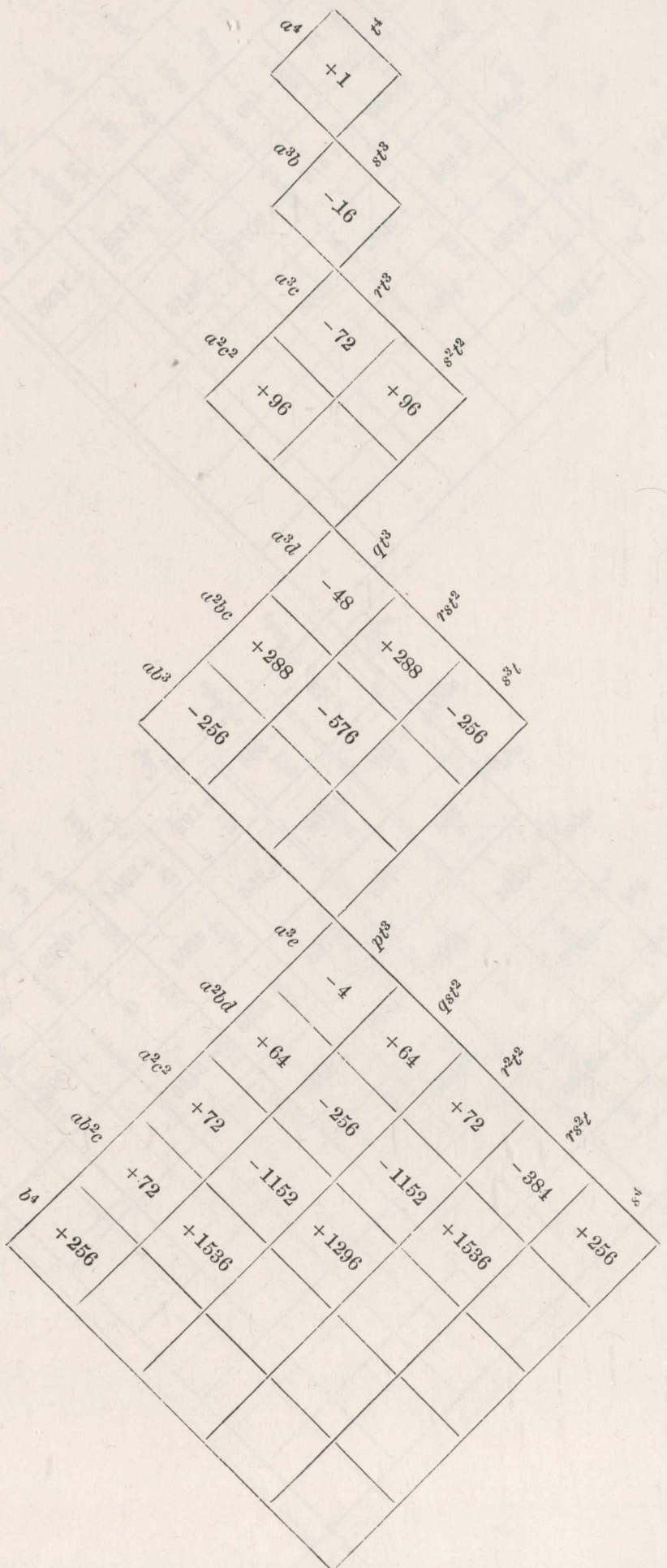


Table (4, 4) continued:

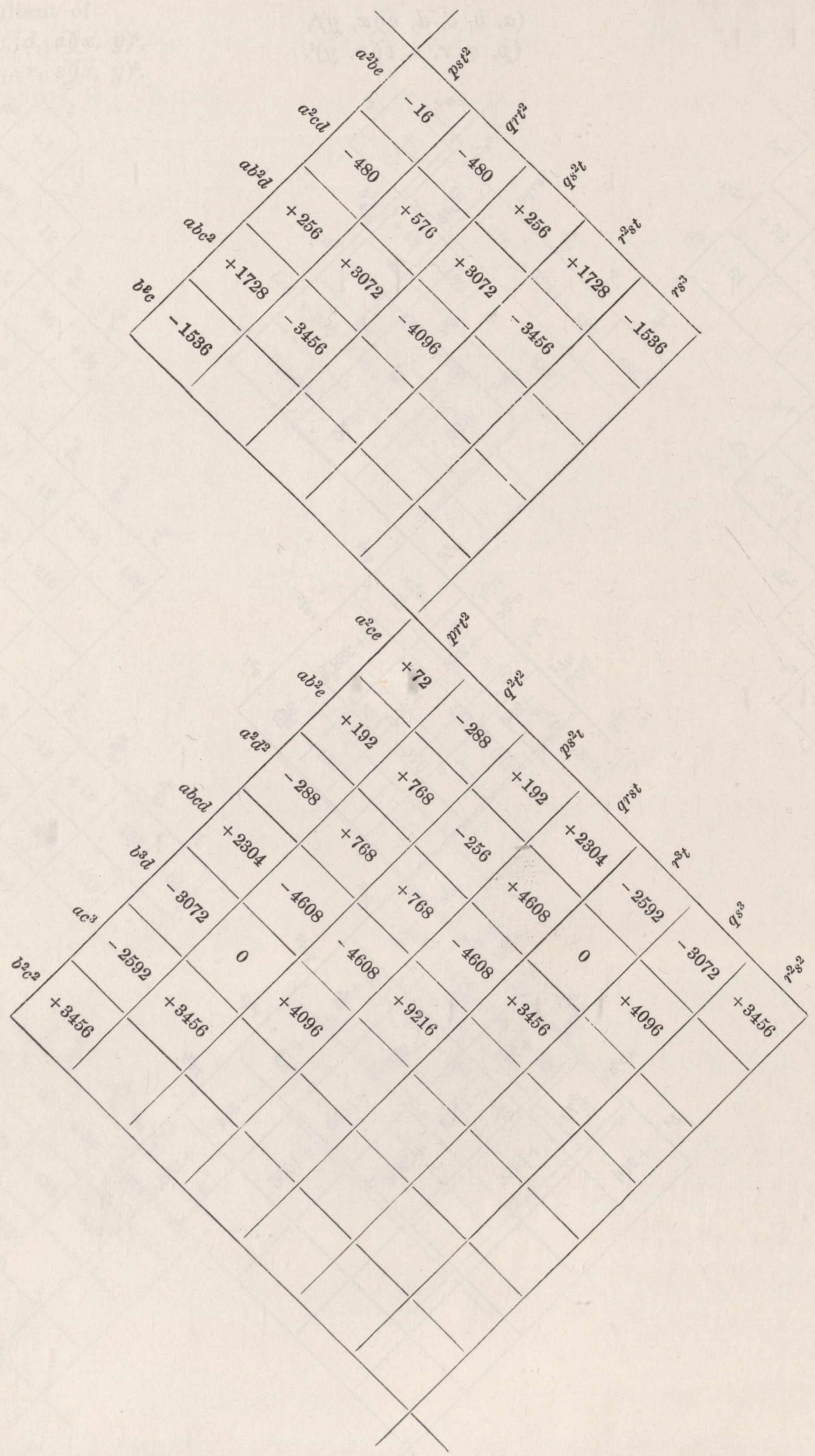




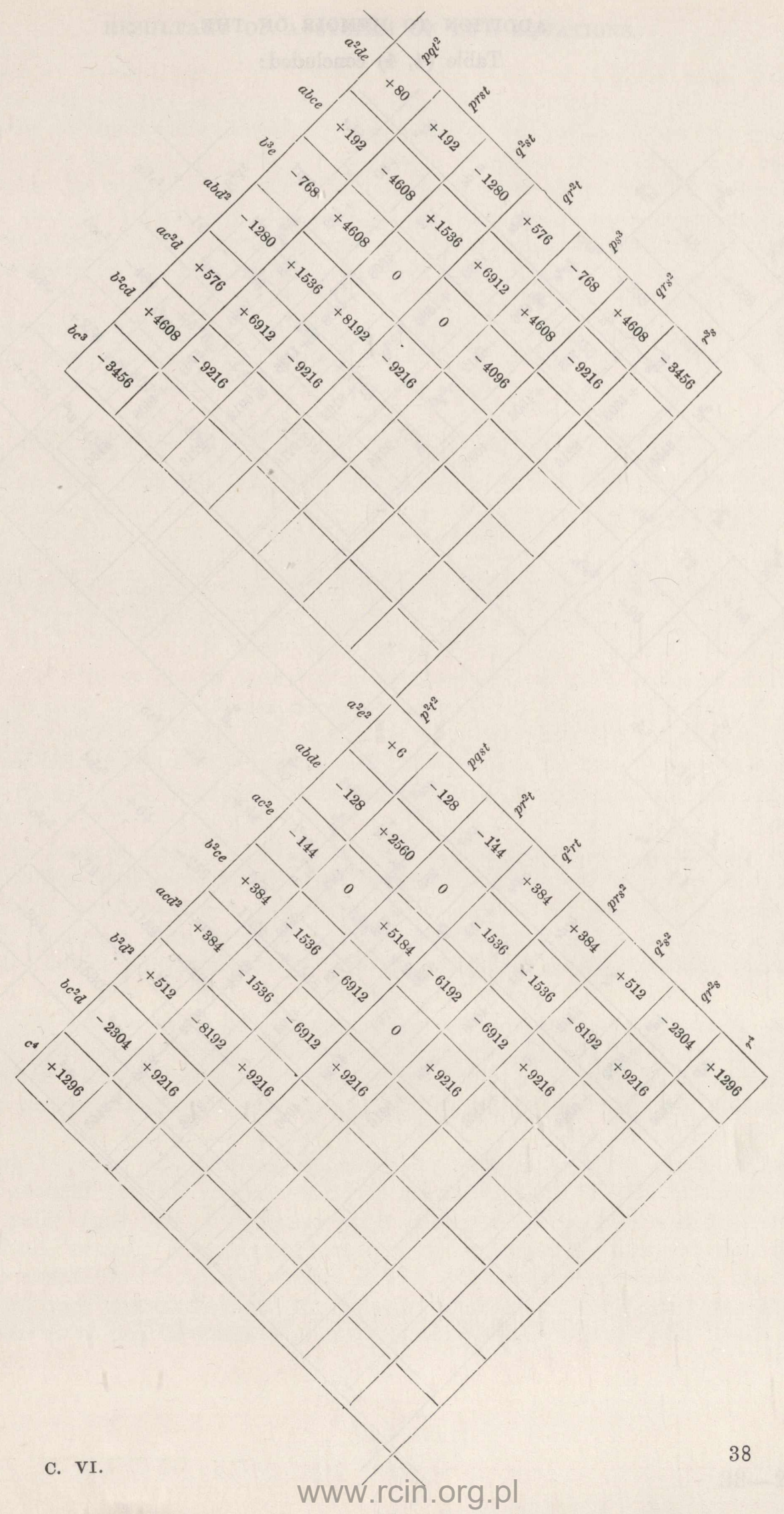


Table $(4,4)$ concluded:

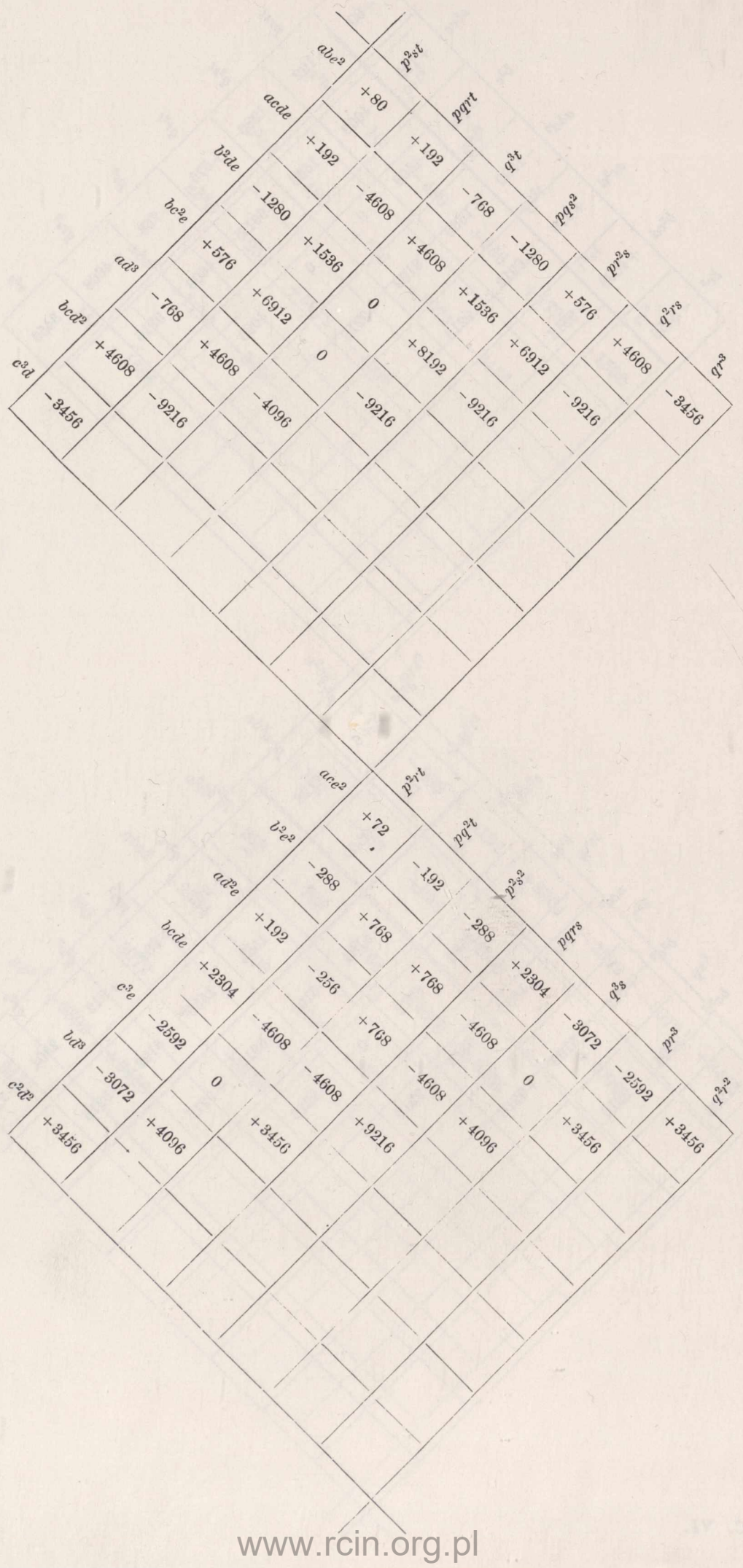



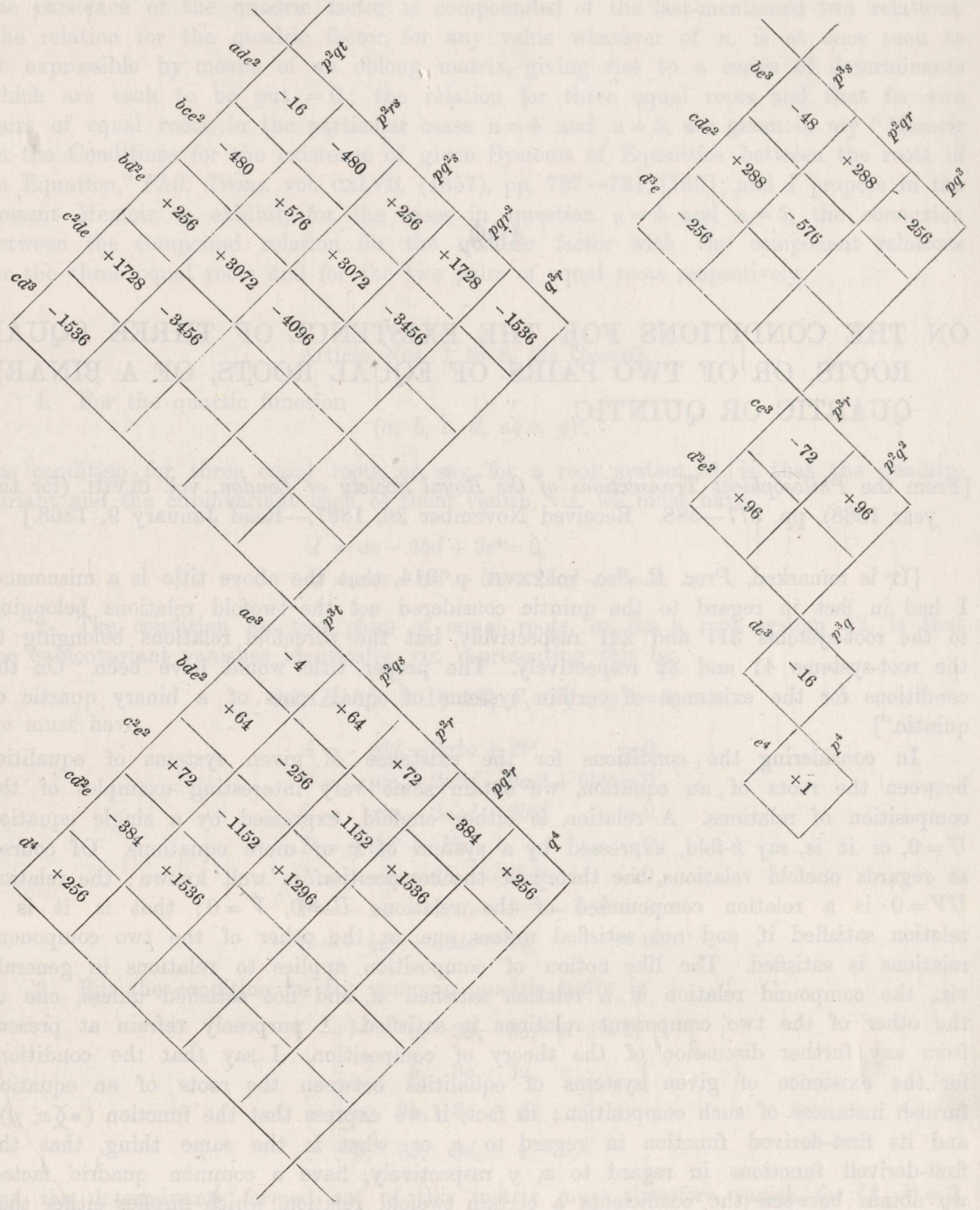